\title{
МОЛЕКУЛЯРНО-ГЕНЕТИЧЕСКАЯ ИЗМЕНЧИВОСТЬ ГЕНОВ 18S-RRNA И 28S-RRNA У ЦЕСТОД РОДА BOTHRIOCEPHALUS RUD., 1808 (CESTODA: BOTHRIOCEPHALIDEA) ИЗ РЫБ ЧЁРНОГО МОРЯ
}

\section{Ю.В. Слынько}

к.б.н., ведущий научный сотрудник отдела биофизической экологии

Т.А. Полякова

к.б.н., старший научный сотрудник отдела экологической паразитологии

ФИЦ Институт биологии южных морей

им. А.О. Ковалевского РАН, г. Москва

Цестода, Bothriocephalidea, молекулярногенетическая идентификация, 18S, 28S, филогения, комплекс видов,

Чёрное море

Cestode,

Bothriocephalidea, molecular genetic identification, $18 S$, 28S, phylogeny, species complex, the Black Sea

\section{Е.Е. Слынько (фото)}

к.б.н., старший научный сотрудник лаборатории экологии водных беспозвоночных

ФГБУН Институт биологии внутренних вод им. И.Д. Папанина $\mathrm{PAH}$, п. Борок

старший преподаватель кафедры зоотехнии

ФГБОУ ВО Ярославская ГСХА, г. Ярославль

старший научный сотрудник ФИЦ Институт биологии южных морей им. А.О. Ковалевского РАН, г. Москва

Впервые представители отряда Bothriocephalidea у костистых рыб Чёрного моря были обнаружены в конце 19 века [1] и определены как Bothriocephalus scorpii Müller, 1776 (Cooper, 1917). Первое морфологическое схематическое описание этого вида цестод от черноморских рыб появилось только в конце 20 века [2]. В целом, до недавнего времени у хрящевых и костистых рыб Чёрного моря определяли 4 вида из семейства Bothriocephalidae (Blanchard, 1849): B. scorpii, паразитирующий у скорпены Scorpaena porcus (Linnaeus, 1758); B. gregarius (Renaud, Gabrion \& Pasteur, 1983) - у черноморской камбалы Scophthalmus maeoticus (Pallas, 1814); B. claviceps (Goeze, 1782) - у речного угря Anguilla anguilla (Linnaeus, 1758) и Ptychobothrium atherinae $[3,4]-$ у атерины Atherina boyeri (Risso, 1810) [5, 6]. Основная проблема с двумя черноморскими видами паразитов костистых рыб - B. gregarius и с B. scorpii - это отсутствие полноценных описаний, не позволивших окончательно установить систематическое положение данных видов. Видовое определение B. gregarius у черноморской камбалы из Чёрного моря [7] было выполнено не на морфологических признаках, а по данным биохимической генетики. И только в 2003 году было представлено основательное морфологическое описание этого 
вида [8]. В настоящее время вид «B. sсоrpii» считается видом-комплексом [9-11], в его составе выделяют B. gregarius, B. barbatus [12], B. renaudii [13] и B. funiculus [14]. Эти виды признаны как nomina nuda, поскольку их оригинальные описания не соответствуют требованиям Международного кодекса зоологической номенклатуры (1999 год, статья 13) $[11,15]$. Таким образом, для Азово-Черноморского бассейна известно существование одного видового комплекса и трёх видов цестод рода Bothriocephalus Rud., 1808: комплекс B. «scorpii» (Mueller, 1779), виды - B. claviceps (Goeze, 1782) и B. atherinae (Tschernischenko, 1949) [4]. В 1984 году Рено с соавторами [9], анализируя генетико-биохимические различия цестод комплекса B. scorpii, паразитирующих в камбалах большой ромб (Psetta maxima) и гладкий ромб (Scophthalmus rhombus), обосновали существование ещё одного вида комплекса - Bothriocephalus gregarius. При этом, если валидность известных ранее видов не вызывает сомнений, то достоверность видового статуса B. gregarius, начиная со второй половины 2000-х годов, стала подвергаться сомнению на том основании, что нет достаточных подтверждений его описания $[15,18]$. Полученные молекулярно-генетические данные по ряду рибосомных генов (18s и ITS1) достаточно уверенно указывали на монофилитичность $B$. gregarius и B. scorpii [10]. С другой стороны, отдельные авторы на основании морфологических описаний настаивают на таксономической независимости данного вида [8].

Соответственно основной задачей нашего исследования был молекулярно-генетический анализ генов 18S-rRNA и 28S-rRNA у цестод из скорпены Scorpaena porcus и от черноморской камбалы Scophthalmus maeoticus бассейна Чёрного моря.

\section{Материал и методы}

Цестоды рода Bothriocephalus были собраны с двух хозяев - один экземпляр был взят из скорпены (Scorpaena porcus) и 3 экземпляра - от двух особей черноморской камбалы, Scophthalmus maeoticus.

Тотальную ДНК выделяли при помощи набора innuPREP DNA Mini Kit (компания Analytik Jena, Германия). В качестве амплификационных смесей использовали готовые лиофилизованные реакционные смеси без праймеров (мастермиксы), предназначенные для проведения амплификаций ДНК в объёме 20 мкл (ООО «Научно-производственная фирма «Генлаб», Мо- сква). Мастермиксы для проведения отдельной реакции содержали все необходимые для реакции компоненты, включая ингибированную для «горячего старта» Таq ДНК полимеразу, dNTP и краску для электрофореза (OОO «Научно-производственная фирма «Генлаб», Москва). В качестве генетических маркеров использовали фрагменты по генам 18S-rRNA и 28S-rRNA длиной 1500 п.н. и 600 п.н. соответственно. Амплификацию фрагмента 18S-rRNA осуществляли в присутствии двух праймеров:

18S-rRNA F1 (5'-TCCTGCCAGTAGTCATATGCTTG-3') n 18S-rRNA R1 (5'- GCCATGCACCACCAACCAC-3') [17].

Амплификацию фрагмента 28S-rRNA проводили в присутствии следующих праймеров:

28S-rRNA C1 (5'-ACCCGCTGAATTTAAGCAT-3') и 28S-rRNA C3 (5'- CTCTTCAGAGTACTTTTCAAC-3') [18].

Предварительно были подобраны оптимальные условия для ПЦР, поскольку первоначальные оказались неэффективными. Полимеразную цепную реакцию по фрагменту гена 18S-rRNA осуществляли в следующем температурном режиме: $94^{\circ} \mathrm{C}-3$ мин., $94^{\circ} \mathrm{C}-30$ сек., $61^{\circ} \mathrm{C}-45$ сек., $72^{\circ} \mathrm{C}-$ 60 сек., общее количество циклов - 25, финальная элонгация при $72^{\circ} \mathrm{C}-10$ мин. Условия ПЦР по фрагменту гена 28S-rRNA были следующие: $95^{\circ} \mathrm{C}-4$ мин., $95^{\circ} \mathrm{C}-30$ сек., $58^{\circ} \mathrm{C}-30$ сек., $72^{\circ} \mathrm{C}-$ 30 сек., общее количество циклов - 30, финальная элонгация при $72^{\circ} \mathrm{C}-10$ мин. Присутствие специфического ампликона детектировали электрофоретическим разделением в $2 \%$ агарозном геле. Секвенирование полученных ПЦР-продуктов в прямом и обратном направлении проводилось на базе ЗАО «Евроген Ру» (Москва). Выравнивание и анализ полиморфизма нуклеотидных последовательностей проводили в программных пакетах BioEdit 5.0.9.1 [19]. Филогенетическое древо с расчётом бутстреп-поддержек узлов ветвления (1000 репликаций) строили в программе MEGA 7.0 с применением метода «ближайшего соседа» (Neighbor Joining, NJ) [20]. Для сравнения использовали данные по гаплотипам цестод p. Bothriocephalus по 18S-rRNA и 28S-rRNA, взятым из GenBank, NCBI [21].

\section{Результаты и обсуждение}

Нами были проанализированы изменчивость фрагментов двух генов рДНК - IsrDNA (28S) - длиной 312 п.н. и ssrDNA (18S) - 568 п.н. у представителей p. Bothriocephalus из разных хозяев. В результате, как по каждому гену в отдельности, так и при их объединении установ- 
лено, что образец, извлечённый из скорпены (№№ деп. В NCBI - MH011407 - 18S и MH000375 28S), надёжно идентифицируется как относящийся к кладе, содержащей B. timii, B. scorpii и B. australis, p-расстояние между нашим образцом и другими видами этой группы не превышает 1,6\% (рис. 1, табл. 1). Остальные три образца МH011408, МH011409, МН011410 (для гена 18s) и МН000376 (для гена 28s) сформировали отдельную кладу, состоящую из двух субклад: одна включает образцы МН011409 и МН011410, другая - образец МH011408 (здесь и далее мы указываем только регистрационные номера для гена 18s).

Bсе ветви обозначены регистрационными номерами собственных фрагментов и фрагментов других видов цестод из NCBI (см. расшифровку обозначений в табл. 1). Числовые значения на разветвлениях отражают уровень бутстреп-поддержки. Внизу указана единица измерения длин ветвей - 0.01 нуклеотид. KR780885+ KR780929 - Bothriocephalus timii;
AF286942+ AJ228776 - Bothriocephalus scorpii; KR780910+KR780957 - Bothriocephalus claviceps (Out); KR78088+KR780886 - Bothriocephalus australis; MH000375+MH011407 - образец цестоды из скорпены, МН000376+МН011408, $\mathrm{MH} 000376+\mathrm{MH} 011409$, MH000376+MH011410 образцы из черноморской камбалы.

Следует также отметить, что виды Bothriocephalus timii $и$ Bothriocephalus scorpii дистанцированы всего лишь на 0,5\%, а Bothriocephalus timii и Bothriocephalus australis - на 0,6\%. Дивергенция остальных образцов (из черноморской камбалы) от рассматриваемых трёх видов колебалась от 4,0\% до 5,1\%. Гаплотипы вида Bothriocephalus claviceps составили внешнюю группу, р-расстояние от которого как наших всех образцов, так и рассматриваемых видов комплекca «scorpio» не опускалось ниже 26,3\%. Полученные данные дают полное основание судить о том, что рассматриваемые образцы цестод, как из скорпены, так и черноморской камбалы относятся к таксономическому комплексу Bothriocephalus

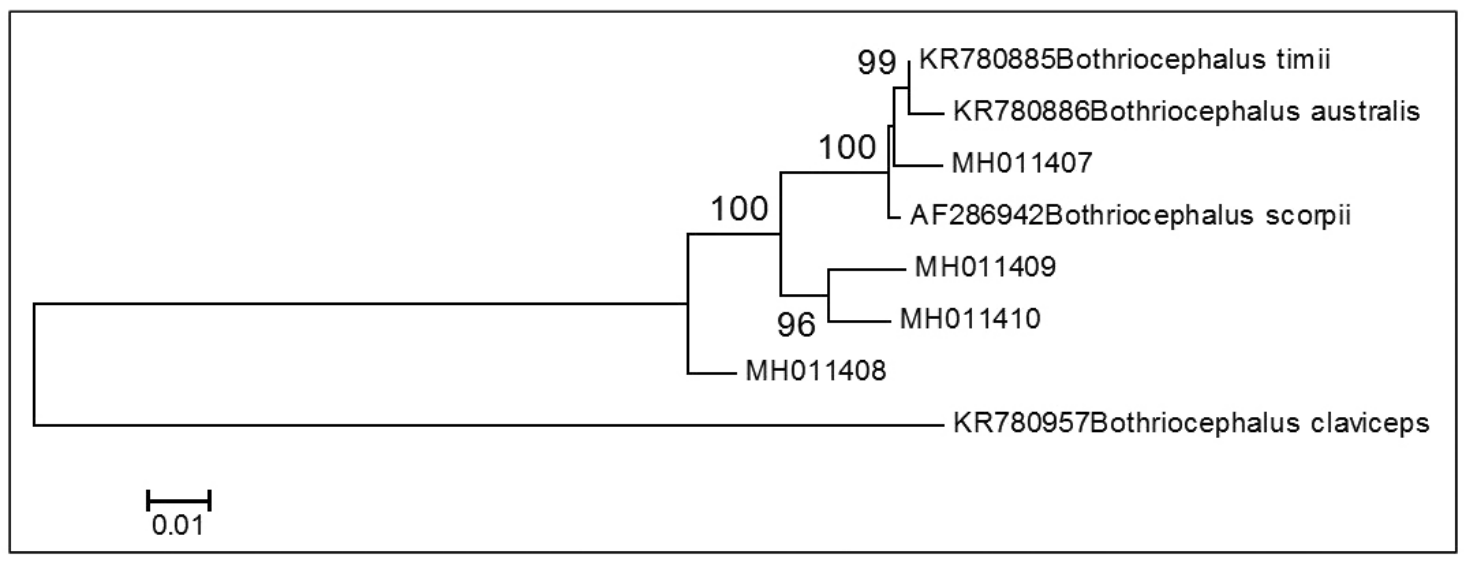

Рисунок 1 - Дерево, построенное методом Neighbor-Joining на основании объединённых данных о нуклеотидных последовательностях фрагментов генов 18s и 28s рДНК видов рода Bothriocephalus

Таблица 1 - Оценка эволюционной дивергенции между 8 фрагментами длиной 879 п.н. объединённых последовательностей генов $18 \mathrm{~s}$ и 28s, выраженные в р-расстояниях (в \%)

\begin{tabular}{|c|c|c|c|c|c|c|c|c|}
\hline № & Фрагмент & \multicolumn{7}{|c|}{ Эволюционная дивергенция, \% } \\
\hline 1 & MH000375+MH011407 & 1 & 2 & 3 & 4 & 5 & 6 & 7 \\
\hline 2 & KR780885+KR780929 & 1,0 & & & & & & \\
\hline 3 & MH000376+MH011408 & 5,1 & 4,6 & & & & & \\
\hline 4 & AF286942+AJ228776 & 1,1 & 0,5 & 4,1 & & & & \\
\hline 5 & MH000376+MH011409 & 4,8 & 4,2 & 4,0 & 3,8 & & & \\
\hline 6 & MH000376+MH011410 & 4,3 & 4,1 & 4,0 & 3,6 & 2,3 & & \\
\hline 7 & KR780910+KR780957 & 29,2 & 29,1 & 26,3 & 29,5 & 29,6 & 28,7 & \\
\hline 8 & KR78088+KR780886 & 1,6 & 0,6 & 5,1 & 1,0 & 4,8 & 4,7 & 29,5 \\
\hline
\end{tabular}


«scorpii» и, несомненно, имеют монофилетическое происхождение.

Вместе с тем, дистанцированность объединённых гаплотипов цестод из черноморской камбалы на уровне 4-5\% р-расстояний, а также значения бутстрепа позволяют полагать их близнецовыми видами (или подвидами) в пределах рода, по аналогии с генами мтДНК $[22,23]$. Теоретически, это можно было бы считать косвенным доказательством справедливости ранее высказанного мнения [8], о принадлежности цестод из черноморской камбалы к виду Bothriocephalus gregarius. С другой стороны, использование данных по гену 18 s из NCBI [10] свидетельствует о значительной дистанцированности их гаплотипов от наших, превышая дистанцированность вида Bothriocephalus claviceps приблизительно в 2 раза, что свидетельствует о полной таксономической независимости Bothriocephalus gregarius. И хотя авторы обосновывают идею монофилитичности Bothriocephalus gregarius и Bothriocephalus scorpii, необходимо учитывать, что в публикации Верне с соавторами [10] особо подчеркнуто, что структура ветвления крайне неудачна среди группы близкородственных видов B. barbutus, B. gregarius, B. jimiculus и B. scorpii. При этом указано, что эти виды могут быть монофилетическими на основании значения бутстрепа (около 80\%), а при этом никакой другой кластер не поддерживается на уровне начальной загрузки выше 70\%. Если последовательности из фрагмента 18s рДНК при выравнивании были неоднозначными, в частности для регионов с вставками или удалениями, то все сайты, включая эти разрывы (введение, удаление), были в рассматриваемой работе удалены из филогенетического анализа и проводились с использованием комбинированных последовательностей, полученных из частичной 18s рДНК.
Также следует заметить, что филогенетический анализ проводился с использованием весьма ранней версии программы PAUP 3.1. I. (Swofford 1993).

\section{Вывод}

Ввиду вышеизложенного, мы полагаем, что наиболее достоверной версией молекулярногенетической идентификации представленных образцов цестод из скорпены и черноморской камбалы Чёрного моря будет констатация факта их принадлежности к комплексу Bothriocephalus «scorpii» с допущением существования подвидов.

\section{Благодарности}

Работа выполнена при частичной финансовой поддержке в рамках гос. тем № АAААА18-118020790229-7 «Структурно-функциональная организация, продуктивность и устойчивость морских пелагических экосистем», № АAАА-А 18-118021350003-6 «Исследование механизмов управления продукционными процессами в биотехнологических комплексах с целью разработки научных основ получения биологически активных веществ и технических продуктов морского генезиса» и № АААА-А18-118012690105-0 «Фауна, систематика и биология водных беспозвоночных континентальных вод», № АAАА-А18-118020890074-2 «Закономерности формирования и антропогенная трансформация биоразнообразия и биоресурсов АзовоЧерноморского бассейна и других районов Мирового океана», № госрегистрации ААААА16-116090850007-7 «Повышение эффективности использования биологических и породных ресурсов различных видов домашних и сельскохозяйственных животных, рыб и птиц».

\section{תumepamypa}

1. Ульянин, В.Н. Материалы для фауны Черного моря [Текст] / В.Н. Ульянин // Изв. о-ва любит. естеств., антропол. и этнограф. - 1872. - Т. 9. - Вып. 1. - С. 79-32.

2. Погорельцева, Т.П. Материалы к изучению ленточных червей - паразитов рыб Чёрного моря [Текст] / Т.П. Погорельцева // Труды КБС. - 1960. - Вып. 16. - С. 143-159.

3. Чернышенко, Л.В. Материалы к хирургической анатомии двенадцатиперстной кишки [Текст]: автореф. дисс. ... канд. мед. наук / Чернышенко Л.В. - Киев, 1949. - С. 16-18.

4. Корнюшин, В.В. О гетерогенности рода Bothriocephalus (Cestoda, Pseudophyllidea) [Teкст] / В.В. Корнюшин, О.П. Кулаковская // Вестник зоологии. - 1984. - Вып. 3. - С. 11-15.

5. Гаевская, А.В. Определитель паразитов позвоночных животных Чёрного и Азовского морей [Текст] / А.В. Гаевская, А.В. Гусев, С.Л. Делямуре и др. - Киев: «Наукова Думка», 1975. - С. 296-364.

6. Мирошниченко, А.И. Паразиты морских рыб и беспозвоночных [Текст] / А.И. Мирошниченко // Карадаг. Гидробиологические исследования: сб. науч. тр., посвящ. 90-летию Карадаг. науч. станции им. Т.И. Вяземского и 25-летию Карадаг. природного заповедника НАН Украины. - Симферополь: СОНАТ, 2004. Кн. 2. - C. 468-495.

Молекулярно-генетическая изменчивость генов 18S-rRNA и 28S-rRNA у цестод рода Bothriocephalus Rud., 1808 (Cestoda: Bothriocephalidea) из рыб Чёрного моря 
7. Солонченко, А.И. Систематическое положение цестоды «Bothriocephalus scorpii» от камбал Черного и Азовского морей и ее генетические вариации [Текст] / А.И. Солонченко, И.И. Руднева // Экология моря. 1997. - Вып. 46. - С. 75-77.

8. Полякова, Т.A. Обнаружение цестод рода Bothriocephalus (Rud., 1802) в черноморском скате Raja clavata (L.) [Tекст] / T.A. Полякова // Экология моря. - 2003. - Вып. 64. - С. 30-34.

9. Renaud, F. Le complexe Bothriocephalus scorpii (Mueller, 1776): Différenciation des espèces parasites du Turbot (Psetta maxima) et de la Barbue (Scophthalmus rhombus). Étude des fractions protéiques et des complexes antigéniques [Texte] / F. Renaud, C. Gabrion, B. Romestand // Ann. Parasitol. Hum. Comp. - 1984. Vol 59. - № 2. - P. 143-149.

10. Verneau, O. Molecular relationships between closely related species of Bothriocephalus (Cestoda: Platyhelminthes) [Text] / O. Verneau, F.M. Catzeflis, F. Renaud // Molecular phylogenetics and evolution. - 1997. Vol. 7. - No. 2. - P. 201-207.

11. Kuchta, R. Bothriocephalidea / R. Kuchta, T. Scholz // Planetary Biodiversity Inventory (2008-2017): Tapeworms from ther Bowels of the Earth / J.N. Caira, K. Jensen (eds); University of Kansas, Natural History Museum. Lawrence. KS. USA, 2017. - Special Publication No. 25. - Pp. 29-45.

12. Renaud, F. Le complexe Bothriocephalus (Mueller, 1776): Différenciation par électrophorèse enzymatique des espèces parasites du turbot (Psetta maxima) et de la barbue (Scophthalmus rhombus) [Texte] / F. Renaud, C. Gabrion, N. Pasteur // C. R. Acad. Sci. - Paris, 1983. - 296. - P. 127-129.

13. Ortega, J.E. Diferenciación genética entre dos poblaciones del complejo Bothriocephalus scorpii (Pseudophyllidea: Bothriocephalidae) [el Texto] / J.E. Ortega, A. Valero // Rev. Ibér. Parasitol. - 1989. - Vol. 49. No. 2. - P. 139-145.

14. Renaud, F. Le complexe Bothriocephalus scorpii (Mueller, 1776) Différenciation des espèces parasites du Turbot (Psetta maxima) et de la Barbue (Scophthalmus rhombus). Étude des fractions protéiques et des complexes antigéniques [Texte] / F. Renaud, C. Gabrion, B. Romestand // Ann. Parasitol. Hum. Comp. - 1984. - Vol 59. - No 2. - P. 143-149.

15. Kuchta, R. Diversity and distribution of fish tapeworms of the «Bothriocephalidea» (Eucestoda) [Text] / R. Kuchta, T. Scholz // Parassitologia. - 2007. - 49. - P. 129-146.

16. Kuchta, R. Suppression of the tapeworm order Pseudophyllidea (Platyhelminthes: Eucestoda) and the proposal of two new orders, Bothriocephalidea and Diphyllobothriidea [Text] / R. Kuchta, T. Scholz, J. Brabec, R.A. Bray // Int. J. Parasitol. - 2008. - 38. - P. 49-55.

17. Littlewood, D.T.J. Small subunit rDNA and the Platyhelminthes: signal, noise, conflict and compromise [Text] / D.T.J. Littlewood, P.D. Olson // Interrelationships of the Platyhelminthes / D.T.J. Littlewood, R.A. Bray (Eds.). - Taylor \& Francis. London, 2001. - P. 262-278.

18. Hassouna, N. The complete nucleotide sequence of mouse $28 \mathrm{~S}$ rRNA gene. Implications for the process of size increase of the large subunit rRNA in higher eukaryotes [Text] / N. Hassouna, B. Michot, J.P. Bachellerie // Nucleic Acids Res. - 1984. - V. 12. - N. 8. - P. 3563-3583.

19. Hall, T.A. BioEdit: a user-friendly biological sequence alignment editor and analysis program for Windows 95/98/NT [Text] / T.A. Hall // Nucl. Acids. - 1999. - Symp. Ser. - No. 41. - P. 95-98.

20. Kumar, S. MEGA7: Molecular Evolutionary Genetics Analysis Version 7.0 for Bigger Datasets [Text] / S. Kumar, G. Stecher, K. Tamura // Mol Biol Evol. - 2016. - V. 33. - N. 7. - P. 1870-1874.

21. NCBI [Электронный ресурс]. - Режим доступа: http: //www.ncbi.nlm.nih.gov/.

22. Kartavtsev, Y. Ph. Sequence divergence at mitochondrial genes in animals: Applicability of DNA data in genetics of speciation and molecular phylogenetics [Text] / Y.Ph. Kartavtsev // Marine Genomics. - 2011. V. 49. - P. 71-81.

23. Kartavtsev, Y.Ph. Sequence diversity at Cyt-b and Co-1 mtDNA genes in animal taxa proved Neo-Darwinism [Text] / Y.Ph. Kartavtsev // J. Phylogenet. Evol. Biol. - 2013. - N. 1:1-5.

24. Swofford, D.L. PAUP: Phylogenetic analysis using parsimony. Version 3.1.1. Computer program distributed by Illinois Natural History Survey [Text] / D.L. Swofford. - Champaign, 1993.

\section{References}

1. UI'yanin, V.N. Materialy dlya fauny Chernogo morya [Tekst] / V.N. UI'yanin // Izv. o-va lyubit. estestv., antropol. i etnograf. - 1872. - T. 9. - Vyp. 1. - S. 79-32.

2. Pogorel'ceva, T.P. Materialy k izucheniyu lentochnyh chervej - parazitov ryb CHyornogo morya [Tekst] / T.P. Pogorel'ceva // Trudy KBS. - 1960. - Byp. 16. - S. 143-159.

3. Chernyshenko, L.V. Materialy k hirurgicheskoj anatomii dvenadcatiperstnoj kishki [Tekst]: avtoref. diss. ... kand. med. nauk / Chernyshenko L.V. - Kiev, 1949. - S. 16-18. 
4. Kornyushin, V.V. O geterogennosti roda Bothriocephalus (Cestoda, Pseudophyllidea) [Tekst] / V.V. Kornyushin, O.P. Kulakovskaya // Vestnik zoologii. - 1984. - Vyp. 3. - S. 11-15.

5. Gaevskaya, A.V. Opredelitel' parazitov pozvonochnyh zhivotnyh CHyornogo i Azovskogo morej [Tekst] / A.V. Gaevskaya, A.V. Gusev, S.L. Delyamure i dr. - Kiev: «Naukova Dumka», 1975. - S. 296-364.

6. Miroshnichenko, A.l. Parazity morskih ryb i bespozvonochnyh [Tekst] / A.l. Miroshnichenko // Karadag. Gidrobiologicheskie issledovaniya: sb. nauch. tr., posvyashch. 90-letiyu Karadag. nauch. stancii im. T.I. Vyazemskogo i 25-letiyu Karadag. prirodnogo zapovednika NAN Ukrainy. - Simferopol': SONAT, 2004. Kn. 2. - S. 468-495.

7. Solonchenko, A.I. Sistematicheskoe polozhenie cestody «Bothriocephalus scorpii» ot kambal CHernogo i Azovskogo morej i ee geneticheskie variacii [Tekst] / A.I. Solonchenko, I.I. Rudneva // Ekologiya morya. - 1997. Vyp. 46. - S. 75-77.

8. Polyakova, T.A. Obnaruzhenie cestod roda Bothriocephalus (Rud., 1802) v chernomorskom skate Raja clavata (L.) [Tekst] / T.A. Polyakova // Ekologiya morya. - 2003. - Vyp. 64. - S. 30-34.

9. Renaud, F. Le complexe Bothriocephalus scorpii (Mueller, 1776): Différenciation des espèces parasites du Turbot (Psetta maxima) et de la Barbue (Scophthalmus rhombus). Étude des fractions protéiques et des complexes antigéniques [Texte] / F. Renaud, C. Gabrion, B. Romestand // Ann. Parasitol. Hum. Comp. - 1984. Vol 59. - No 2. - P. 143-149.

10. Verneau, O. Molecular relationships between closely related species of Bothriocephalus (Cestoda: Platyhelminthes) [Text] / O. Verneau, F.M. Catzeflis, F. Renaud // Molecular phylogenetics and evolution. - 1997. Vol. 7. - No. 2. - P. 201-207.

11. Kuchta, R. Bothriocephalidea / R. Kuchta, T. Scholz // Planetary Biodiversity Inventory (2008-2017): Tapeworms from ther Bowels of the Earth / J.N. Caira, K. Jensen (eds); University of Kansas, Natural History Museum. - Lawrence. KS. USA, 2017. - Special Publication No. 25. - Pp. 29-45.

12. Renaud, F. Le complexe Bothriocephalus (Mueller, 1776): Différenciation par électrophorèse enzymatique des espèces parasites du turbot (Psetta maxima) et de la barbue (Scophthalmus rhombus) [Texte] / F. Renaud, C. Gabrion, N. Pasteur // C. R. Acad. Sci. - Paris, 1983. - 296. - P. 127-129.

13. Ortega, J.E. Diferenciación genética entre dos poblaciones del complejo Bothriocephalus scorpii (Pseudophyllidea: Bothriocephalidae) [el Texto] / J.E. Ortega, A. Valero // Rev. Ibér. Parasitol. - 1989. - Vol. 49. No. 2. - P. 139-145.

14. Renaud, F. Le complexe Bothriocephalus scorpii (Mueller, 1776) Différenciation des espèces parasites du Turbot (Psetta maxima) et de la Barbue (Scophthalmus rhombus). Étude des fractions protéiques et des complexes antigéniques [Texte] / F. Renaud, C. Gabrion, B. Romestand // Ann. Parasitol. Hum. Comp. - 1984. Vol 59. - No 2. - P. 143-149.

15. Kuchta, R. Diversity and distribution of fish tapeworms of the «Bothriocephalidea» (Eucestoda) [Text] / R. Kuchta, T. Scholz // Parassitologia. - 2007. - 49. - P. 129-146.

16. Kuchta, R. Suppression of the tapeworm order Pseudophyllidea (Platyhelminthes: Eucestoda) and the proposal of two new orders, Bothriocephalidea and Diphyllobothriidea [Text] / R. Kuchta, T. Scholz, J. Brabec, R.A. Bray // Int. J. Parasitol. - 2008. - 38. - P. 49-55.

17. Littlewood, D.T.J. Small subunit rDNA and the Platyhelminthes: signal, noise, conflict and compromise [Text] / D.T.J. Littlewood, P.D. Olson // Interrelationships of the Platyhelminthes / D.T.J. Littlewood, R.A. Bray (Eds.). - Taylor \& Francis. London, 2001. - P. 262-278.

18. Hassouna, N. The complete nucleotide sequence of mouse $28 \mathrm{~S}$ rRNA gene. Implications for the process of size increase of the large subunit rRNA in higher eukaryotes [Text] / N. Hassouna, B. Michot, J.P. Bachellerie // Nucleic Acids Res. - 1984. - V. 12. - N. 8. - P. 3563-3583.

19. Hall, T.A. BioEdit: a user-friendly biological sequence alignment editor and analysis program for Windows 95/98/NT [Text] / T.A. Hall // Nucl. Acids. - 1999. - Symp. Ser. - No. 41. - P. 95-98.

20. Kumar, S. MEGA7: Molecular Evolutionary Genetics Analysis Version 7.0 for Bigger Datasets [Text] / S. Kumar, G. Stecher, K. Tamura // Mol Biol Evol. - 2016. - V. 33. - N. 7. - P. 1870-1874.

21. NCBI [Elektronnyj resurs]. - Rezhim dostupa: http: //www.ncbi.nlm.nih.gov/.

22. Kartavtsev, Y. Ph. Sequence divergence at mitochondrial genes in animals: Applicability of DNA data in genetics of speciation and molecular phylogenetics [Text] / Y.Ph. Kartavtsev // Marine Genomics. - 2011. V. 49. - P. 71-81.

23. Kartavtsev, Y.Ph. Sequence diversity at Cyt-b and Co-1 mtDNA genes in animal taxa proved NeoDarwinism [Text] / Y.Ph. Kartavtsev // J. Phylogenet. Evol. Biol. - 2013. - N. 1:1-5.

24. Swofford, D.L. PAUP: Phylogenetic analysis using parsimony. Version 3.1.1. Computer program distributed by Illinois Natural History Survey [Text] / D.L. Swofford. - Champaign, 1993. 